\title{
Estado laico, laicidad y laicismo
}

Gonzalo F. Fernández*

\section{Reflexiones sobre una vieja cuestión que quiere reiterarse}

Desde el Concilio Vaticano II ha quedado doctrinariamente concluida la discusión acerca de la confesionalidad del Estado y la libertad religiosa. Sin embargo, en lo que se entiende como "mundo culturalmente cristiano", el conflicto se replantea a raíz de problemas prácticos en los que el ejercicio de la libertad religiosa, en especial por parte de la Iglesia católica, entra en colisión con decisiones de los Estados o con otros puntos de vista. El derecho a la vida y su respeto en todos sus aspectos (aborto, eutanasia, manipulación genética), los dramas derivados de las grandes migraciones, la cuestión ecológica, la lucha contra la pobreza, genera pronunciamientos públicos y acciones concretas por parte de instituciones religiosas, que son entendidas como una indebida intromisión en las responsabilidades de los Estados. Sin embargo, el Papa Benedicto XVI ha hablado en los parlamentos de Alemania y Gran Bretaña, y Francisco en el Congreso de Estados Unidos, donde se han referido a los problemas más acuciantes para la vida y la convivencia humanas. Estos hechos revelan que la naturaleza laica de los Estados, que esos países preservan, no es incompatible con la valoración del mensaje que, a partir de valores religiosos, la Iglesia Católica da a la sociedad.

Doctor en Derecho y Ciencias Sociales, Universidad Nacional de Córdoba, Argentina. Abogado, Universidad Nacional de Córdoba, Argentina. Master of Art in "Government and Public Administration", The American University, Washington DC, EEUU. Secretario General del Instituto Argentino "Jacques Maritain". Contacto: institutomaritainargentina@gmail.com 


\section{El tema en los Evangelios y su consecuencia}

La cuestión de las relaciones entre Iglesia y Estado es parte de la problemática más amplia de las relaciones entre religión y política. Desde la antigüedad, ella ha oscilado desde la subordinación de una a la otra, hasta el respeto mutuo y colaboración de sus respectivas áreas de competencia, pasando por la de absoluta indiferencia de la autoridad civil al hecho religioso.

Es que el mismo protagonista del hecho religioso es el súbdito o ciudadano de la relación política, y tanto la religión como la política generan normas de conducta que pueden coincidir o no.

Contrariamente a lo que se cree, la delimitación de las esferas política y religiosa en el mundo cristiano no es una creación del Iluminismo sino un aporte del cristianismo, receptado de diversas formas en diferentes geografías y épocas. Su punto de partida no está en una reflexión teológica, filosófica o política, sino que está narrado en los Evangelios. Es el bien conocido episodio en el que Jesús indica a los enviados de los fariseos que le preguntan si es lícito pagar tributo al César, que deben dar al César lo que es del César y a Dios lo que es de Dios (Mateo 22, 15-21; Lucas 20, 24 y Marcos 12, 17). De él Maritain (1952) enseña que:

...dicha distinción, al desarrollar sus virtualidades en el curso de la naturaleza humana, ha desembocado en la noción de la naturaleza intrínsecamente laica o secular del cuerpo político", lo que no significa que sea "irreligioso o indiferente" sino que "está únicamente interesado en la vida temporal de los hombres y su bien común temporal".

\section{La relación en la "cristiandad medieval"}

Esa clara distinción tuvo, sin embargo, diferentes grados de aplicación en el mundo cristiano. La conversión del emperador Constantino al cristianismo, en el siglo IV, hizo que se inmiscuyera en la vida de la Iglesia naciente, a la par que colaboraba en su difusión, tipo de relación que se mantuvo durante largos siglos. El emperador no se privaba de llamar a concilios, en los que se discutían las más complejas cuestiones teológicas. 
En una carta dirigida por el Papa Gelasio I al emperador Bizantino Anastasio de Constantinopla entre 494-495, para contener un avance cesaro-papista, dijo que existían dos poderes con los cuales se gobierna soberanamente este mundo: la autoridad (autorictas) sagrada de los pontífices y el poder real (regalis potestas). De allí nació la alegoría de las dos espadas que dio nombre a la teoría, que reconoce la existencia de los dos poderes claramente delimitados. Ella fue una idea central del pensamiento político cristiano de todo el Medioevo, lo que no impidió importantes conflictos entre ambos ámbitos de autoridad. La cuestión era eminentemente práctica y consistía en "saber cuáles eran los criterios que permitirían separar lo temporal de lo espiritual y, sobre todo, quien debía trazar la línea de demarcación" (Ullmann, 1983, p. 133). Estas precisiones se daban en el marco de una sociedad religiosa y culturalmente unificada, que conocemos como "cristiandad".

Luego de la reforma protestante, que quebró la unidad religiosa de Europa occidental, surgió la lucha entre los bandos religiosamente enfrentados, que apaciguaron sus enfrentamientos bajo la consigna “cuius regio, eius religio" (la religión del rey es la del reino y sus súbditos), que se atribuye a Martín Lutero y que identifica comunidad política con religión. Después de la Guerra de los Treinta Años y con la firma de la Paz de Westfalia en 1648, empieza un proceso hacia la libertad religiosa, pues el pensamiento confesional ya no era lo importante, sino la libertad individual, lo que es fruto de la Ilustración. Así va perdiendo fuerza la idea de una Iglesia del Estado y de unidad de Estado y religión, sustituida por la libertad religiosa del individuo contra el Estado y también contra la Iglesia, entendiéndose que todas las confesiones pueden igualmente ser consideradas ante el gobierno, por no tener posiciones encontradas en lo referido a la moral. La tolerancia es, de esa manera, una concesión a los ciudadanos que profesen otras religiones sin que el Estado deje de ser confesional.

\section{De la tolerancia a la libertad religiosa}

Después de la independencia de los Estados Unidos, en 1776, la antigua tradición europea de unidad entre el poder secular y la religión, que también se practicó en las colonias norteamericanas, fue expresamente abolida, y el libre ejercicio de la religión fue garantizado. 
Es interesante la precisión de Christian Starck (1996), profesor de la Universidad Georg August de Götingen, para quien la tolerancia religiosa supone una forma de Estado confesional, que no cesa en reconocer la existencia de una verdad religiosa. En cambio, la libertad religiosa solamente puede reconocerse en un sistema de separación Iglesia-Estado, que se da cuando se implanta en un Estado la convicción de que las cuestiones religiosas no son tareas de competencia estatal, y de que el Estado debe ser neutral.

En el caso de la Revolución francesa, en cambio, los acontecimientos fueron totalmente distintos. Pese a que el art. 10 de la Declaración de los Derechos del Hombre y del Ciudadano garantizaba a todos la libertad religiosa mientras no alterara el orden público, el Estado avanzó paulatinamente sobre la organización de la Iglesia católica hasta que, proclamada la República, fue abiertamente perseguida, sustituido el calendario por otro llamado "civil", y se entronizó la "Diosa Razón" en la Iglesia de Notre Dame y el culto al "Ser Supremo". Es el germen del "laicismo", un movimiento que, bajo la apariencia de exigir el respeto de la religión de cada uno, en realidad procura la eliminación de la religión en la vida pública y su confinamiento al ámbito de la conciencia individual. Esta situación se mantuvo hasta que Napoleón Bonaparte celebró un Concordato con la Iglesia, en 1801. La convivencia entre Estado y religión durante el siglo XIX (particularmente con la Iglesia católica) fue cambiante.

En 1905 se sancionó la ley de separación de la Iglesia y el Estado aún vigente. Nació como una expresión de laicismo militante, heredero de la Ilustración, que se presenta como una ideología que compite con la religión. Paulatinamente su interpretación fue evolucionando, surgiendo el concepto de "laicidad" que, si bien parte del dualismo entre la Iglesia y el Estado, no ignora que los sujetos sometidos a la soberanía del Estado tienen necesidades religiosas, por lo que es permitido que los creyentes practiquen el ejercicio de la religión de modo colectivo y público, dentro del marco del orden público. Sin embargo, el hecho religioso no tiene el mismo trato que en Estados Unidos (Maritain, 1952)2, \begin{tabular}{l}
\hline Maritain destacó en El hombre y el Estado el distinto alcance que la separación de \\
la Iglesia y el Estado tenía (y tiene) en Estados Unidos y en Europa.
\end{tabular} 
lo que se expresa con diversas restricciones a las manifestaciones religiosas públicas, últimamente hacia la comunidad musulmana.

Durante el siglo XIX casi todas las constituciones modernas habían legislado acerca de las relaciones entre el Estado y las religiones, sobre la base de la libertad de profesar creencias y de practicarlas públicamente con algunas restricciones, conforme a diversos modelos.

\section{Clasificación actual de las relaciones Estado e Iglesia (o confesiones religiosas) y la libertad religiosa de sus ciudadanos}

Una vez que la evolución del proceso relacionado en los puntos anteriores ha culminado en la libertad religiosa, las formas de relación entre la Iglesia católica - y, en su caso, de otros cultos- y el Estado ha dado lugar a diferentes clasificaciones.

Por su sencillez y amplia captación del problema, seguimos aquí la clasificación de María Angélica Gelli (2005), para quien esas relaciones Estado-Iglesia pueden configurar tres formas prototípicas: la sacralidad, en la que existe una religión oficial y el Estado asume - dentro del bien común temporal- importantes aspectos del bien espiritual o religioso de la comunidad, convirtiéndose casi en un instrumento de lo espiritual; la secularidad, en la que el Estado reconoce el valor de la religiosidad, pero sin asumir lo espiritual como tarea específica suya, aunque cooperando con las iglesias (acotamos que es lo que también se denomina "laicidad"), y el laicismo, en el que el Estado adopta una actitud de neutralidad respecto del poder religioso, separando drásticamente el poder político del espiritual en las decisiones que toma, agregando, de mi parte, que es una actitud indiferente y a menudo hostil frente al hecho religioso.

Otro aporte interesante lo hace el profesor Carlos Corral Salvador (2004) de la Universidad Complutense de Madrid, quien describe que, mirando en especial las constituciones de los Estados miembros de la Unión Europea, el criterio calificador mínimo de sus sistemas de relacionarse con las iglesias es la existencia o la inexistencia de al menos una religión o Iglesia del Estado, es decir, la "confesionalidad del Estado", la que en Alemania hasta la Primera Guerra Mundial era, en realidad, biconfesionalidad (la confesión luterana o católica según las re- 
giones); mientras que en Rumania, hasta la Segunda Guerra Mundial, era triconfesionalidad (la confesión ortodoxa, católica y protestante). Este sistema de Estado confesional, normal en la antigüedad y en el llamado "Antiguo Régimen", hasta hoy se mantiene en al menos 53 Estados islámicos — nada menos que en una cuarta parte de la ONU, con alrededor de 1.000 millones de personas-. Pero, sorpresivamente, se mantiene dentro de la Unión Europea en seis Estados, que son Inglaterra (la Iglesia anglicana); Dinamarca, Finlandia, Noruega, Suecia [hasta el 2000] (la Iglesia evangélica luterana); y Grecia (la Iglesia ortodoxa). Debemos aclarar, sin embargo, que en los cinco primeros casos es una unión meramente jurídica, prácticamente sin efectos políticos, pues se trata de sociedades altamente secularizadas y con un amplio ámbito de libertad religiosa. Una forma no mencionada es la de "ateísmo de Estado", que se dio en los Estados de Europa oriental antes de 1989 y al presente en Cuba, China y Vietnam: estos casos, puedo acotar, son de "confesionalidad inversa", pues el ateísmo es un sistema de creencias que suplanta a las religiones, limitadas éstas al máximo en su libertad de acción.

\section{Laicidad}

Cabe ahora precisar las coincidencias y diferencias de dos conceptos lingüística e históricamente emparentados, pero que en nuestros días se han diferenciado notablemente: "laicidad" y "laicismo". Debe hacerse la precisión de que ninguno de ellos tiene un sentido unívoco.

La palabra "laicidad" se comenzó a utilizar en Francia para referirse a la prescindencia religiosa del Estado. Se utilizaba indistintamente con "laicismo", aunque desde 1925 adquiere una connotación de neutralidad y colaboración. Cobra relevancia para la Iglesia católica al fin de la Segunda Guerra Mundial, en la que muchos católicos habían participado activamente en la resistencia. La Constitución de la IV República se autodefinía como "laica", lo que provocó problemas de conciencia en muchos católicos. Ese concepto fue asumido por la Constitución de 1958.

El Episcopado francés se pronunció sobre el punto en su carta pastoral del 12 de noviembre de 1945, distinguiendo cuatro acepciones de "laicidad": laicidad respetuosamente neutral, laicidad simplemente profana, laicismo hostil o agnóstico, laicismo neutral e indiferente, ad- 
mitiendo como legítimas las dos primeras. La primera (profanidad o autonomía), se refiere a "proclamar la autonomía soberana del Estado en sus dominios de orden temporal, su derecho a regir por sí solo toda la organización política, administrativa, fiscal y militar de la sociedad temporal". Lo mismo cabe decir respecto de la segunda acepción (neutralidad respetuosa), referida a que, en un país dividido en cuanto a creencias religiosas, cada ciudadano pueda practicar libremente su religión. Ambas acepciones, se precisa, son conforme al pensamiento de la Iglesia.

Numerosas son, a partir de entonces, las ocasiones en que, desde el pensamiento cristiano - y en particular católico-, la palabra es utilizada para relacionarla principalmente a la "independencia y colaboración" con el Estado. Maritain, Murray, Nell-Breuning y Messineo refieren que no es lo mismo "laico que laicizante", "secular que secularizado", "laicisme que laïcité"; "seculier et secularisé que laiciste", "laicizing, secularist, laicized". Tan es así que F. Rossi llega a exclamar, en el Osservatore Romano (28-VIII-1946, 1), "Stato laico, sí; stato laicista, no".

Entre los dignatarios de la Iglesia, por su parte, el Papa Benedicto XVI (2005) abogó por una "laicidad positiva". Con motivo de un encuentro sobre "Libertad y Laicidad", en la ciudad de Nursia, remitió una carta en la que expresaba que la relación entre la Iglesia y el Estado no es de "hostilidad", sino que la "laicidad positiva" garantiza "a cada ciudadano el derecho de vivir su propia fe religiosa con auténtica libertad, incluso en el ámbito público (...) en el respeto de las exigencias del bien común".

De manera similar, y con ocasión de su visita a Francia en septiembre de 2009, en un discurso en el palacio del Elíseo dirigido al entonces presidente Sarkozy y su comitiva, Benedicto XVI (2009) resaltó que, tanto las raíces de Francia como las de Europa, "son cristianas" y abogó por una "laicidad positiva" (término que había utilizado el presidente Sarkozy) para una "comprensión más abierta" de la Iglesia y del Estado, tras precisar que "la desconfianza del pasado se ha transformado en un diálogo sereno y positivo", y que "una nueva reflexión sobre el significado auténtico y la importancia de la 'laicidad' es cada vez más necesaria". En ese sentido, el Papa agregó que "es fundamental insistir en la distinción entre el ámbito político y el religioso, para tutelar tanto la libertad religiosa de los ciudadanos como la responsabilidad del Estado hacia ellos" y, por 
otra parte, tener "una clara conciencia de las funciones insustituibles de la religión para la formación de las conciencias".

\section{Laicismo}

El laicismo es entendido generalmente como una ausencia de relaciones entre las confesiones religiosas y el Estado, a las que éste debe ignorar. Esta posición sustituye a las religiones, haciendo jugar a esa ideología el mismo rol que ella imputaba a las religiones en el pasado. Según este concepto de "laicismo", no puede haber capillas o capellanes en los hospitales o cuarteles o prisiones, ni debe haber colaboración entre las autoridades religiosas y civiles. Tampoco se admite cooperación económica para los establecimientos escolares gestionados por los cultos religiosos, en el caso de que sean admitidos.

Algunas doctrinas laicistas negativas llegan a criticar que las instituciones religiosas den indicaciones a los fieles sobre asuntos de actualidad con trasfondo religioso, como el aborto o la eutanasia o la homosexualidad. Se niega así a las iglesias y sus autoridades, por el mero hecho de ser tales, un derecho tan fundamental como es la libertad de expresión. Sería una discriminación por motivos religiosos que los obispos no pudieran expresar la doctrina de la Iglesia católica sobre determinados asuntos.

Las doctrinas laicistas negativas más radicales pretenden prohibir que haya símbolos o manifestaciones religiosas públicas, como crucifijos o procesiones, o que las autoridades públicas asistan a ceremonias religiosas, como bendiciones de edificios o misas. La Declaración Universal de los Derechos Humanos, promulgada por las Naciones Unidas en 1948, en su artículo 18, garantiza a todas las personas la "libertad de manifestar su religión o creencia, individual y colectivamente, tanto en público como en privado".

En el ya mencionado documento de noviembre de 1945, el episcopado francés rechazó por incompatibles con la doctrina de la Iglesia las acepciones tercera y cuarta del concepto de "laicidad". Respecto de la tercera, que designa como "laicidad agnóstica u hostil" - y se refiere al comunismo, entonces poderoso en ese país-, afirma que

si la laicidad del Estado es una doctrina filosófica que encierra una perfecta concepción materialista y atea de la vida humana y de la 
sociedad, define un sistema de gobierno político que impone esa concepción a los funcionarios hasta en su vida privada, a las escuelas del Estado, a la nación entera, nos erguimos, con todas nuestras fuerzas, contra esa doctrina; la condenamos en nombre de la verdadera misión del Estado y de la misión de la Iglesia.

Finalmente, ese documento cuestiona también lo que llama "laicismo indiferente", para el cual "la laicidad del Estado significa la voluntad del Estado de no someterse a ninguna moral superior y de no reconocer sino su interés como regla de acción".

\section{Autonomía y cooperación}

En las últimas décadas, en el mundo occidental y culturalmente cristiano, las relaciones del Estado con la Iglesia católica y otros cultos religiosos han tendido a regularse por principios de autonomía y cooperación, en el marco de una amplia libertad religiosa, lo que no significa que cada tanto no surjan situaciones de tensión, como recientemente, en Argentina, con motivo de la discusión de la ley del aborto, mucho más permisiva que la existente hasta el momento según el Código Penal de 1921.

Cuando Maritain escribió El hombre y el Estado, en 1949, fijó algunas posiciones que, podemos decir, se acercan mucho a la situación existente en el ámbito cultural de Occidente, aunque lamentablemente con sociedades mucho más secularizadas que las de entonces. Ello ha sido posible por cambios en las posiciones de la Iglesia, especialmente desde el Concilio Vaticano II, y porque las posiciones laicas y aun laicistas se han abierto con más comprensión al hecho religioso ${ }^{3}$. Así, Maritain (1952) refiere como "formas específicas de la cooperación mutua" entre el "cuerpo político" (concepto que aproximadamente equivale al de Estado en un sentido amplio), el del "reconocimiento y garantía por parte del Estado de la plena libertad de la Iglesia" (p. 200), y "pidiendo la ayuda de la Iglesia para el bien común temporal” (p. 202).

\footnotetext{
3 Es notable la referencia del filósofo alemán Jurgen Habermas al aporte de la religión cristiana a la cultura occidental, aun a la que llama "sociedad postsecular, en su intervención en el famoso debate con Joseph Ratzinger -después Benedicto XVI- en la Academia Católica de Baviera, en enero de 2004. Cf. Entre razón y religión, Fondo de Cultura Económica, Méjico, 2008.
} 
Podemos concluir diciendo, con Maritain (1952), que, en este mundo secularizado, la separación de Iglesia y Estado (diríamos un "Estado laico") significa,

...junto con la negativa a conceder a ninguna confesión religiosa una preferencia sobre las demás y a establecer una religión del Estado, una distinción entre el Estado y las Iglesias que es compatible con las buenas relaciones y la cooperación mutua. (p. 206)

\section{Referencias bibliográficas}

Maritain, J. (1952). El hombre y el Estado. Buenos Aires: Editorial Kraft.

Ullmann, W. (1983). Historia del pensamiento político en la Edad Media. Barcelona: Editorial Ariel.

Starck, C. (Mayo-agosto 1996). Raíces históricas de la libertad religiosa moderna. Revista Española de Derecho Constitucional, 16(47), 9-27. Recuperado de https://dialnet.unirioja.es/descarga/articulo/79551.pdf.

Gelli, M. A. (2005). Espacio público y religión en la Constitución Argentina. Laicismo y laicidad en una sociedad plural. La Ley, 2005-F, 1397).

Corral Salvador, C. (2004). Laicidad, aconfesionalidad, separación, ¿son lo mismo? Revista de la Universidad Complutense de Madrid "UNISCI discussion papers", octubre de 2004". Recuperado de https://www.ucm.es/data/cont/media/www/ pag-72535/Corral8.pdf

Benedicto XVI. (2005). A favor de una "laicidad positiva". Recuperado de http://es.catholic.net/op/articulos/27916/benedicto-xvia-favor-de-una-laicidad-positiva.html\#modal

Benedicto XVI. (2009). La laicidad en sí misma no es contradictoria con la fe. Recuperado de: http://www.elmundo.es/elmundo/2008/09/12/internacional/1221211673.html 